\title{
Characteristics of In-Hospital Mortality among Patients with Acute Coronary Syndrome: A Single-Center Study in West Java, Indonesia
}

\author{
Dennis Bonang Tessy, ${ }^{1}$ Miftah Pramudyo, ${ }^{2}$ Charlotte Johanna Cool ${ }^{2}$ \\ ${ }^{1}$ Faculty of Medicine Universitas Padjadjaran, Indonesia ${ }^{2}$ Department of Cardiology and Vascular \\ Medicine Faculty of Medicine Universitas Padjadjaran/Dr. Hasan Sadikin General Hospital \\ Bandung, Indonesia
}

\section{Abstract}

Background: Acute Coronary Syndrome (ACS) is a severe manifestation of coronary artery disease, classified into unstable angina (UA), non-ST-segment elevation myocardial infarction (NSTEMI), and ST-segment elevation myocardial infarction (STEMI). In-hospital mortality in patients with ACS remains high despite the advancement of therapy. This study aimed to evaluate the characteristics of in-hospital mortality among ACS patients in West Java, Indonesia.

Methods: This descriptive cross-sectional study analyzed retrospective secondary data of ACS patients who died during hospitalization in the period of July 2018 to June 2019 that were recorded in the ACS registry.

Results: A total of 17 patients died during hospitalization in the study period. The mean age was 64.1 years, predominantly female $(n=10)$. The prevalent diagnoses were STEMI $(n=11)$ and NSTEMI $(n=6)$. Interestingly, no patients had died from UA. Hypertension was the most frequent risk factor (11 of 17). Mortality among Killip Class I, II, III, and IV were 7, 5, 1, and 4 patients, respectively. The number of patients who died after underwent Percutaneous Coronary Intervention (PCI) was lower $(n=6)$ than those who did not undergo PCI or those without revascularization $(n=11)$.

Conclusions: The incidence of in-hospital mortality with acute coronary syndrome is high in females, STEMI diagnosis, Killip Class I, and no revascularization.

Keywords: Acute coronary syndrome, characteristics, in-hospital mortality

\section{Introduction}

Acute coronary syndrome (ACS) is a severe, potentially life-threatening manifestation of coronary artery disease (CAD), consists of a spectrum of disorders that are classified into unstable angina (UA), non-ST-segment elevation myocardial infarction (NSTEMI), and ST-segment elevation myocardial infarction (STEMI). ${ }^{1}$ Cardiovascular diseases (CVDs) are the leading cause of death globally, accounting for 17.9 million deaths worldwide in 2016, which represents $31 \%$ of all global deaths. Both CAD and ACS constitute approximately 7 million deaths per year. ${ }^{2}$ In Indonesia, epidemiological studies on ACS are still limited. Based on the Basic Health Research report published by the Indonesian Ministry of
Health in 2019, the prevalence of heart disease in Indonesia varies between provinces, with the prevalence in West Java is $1.62 \%{ }^{3}$

The mortality risk scoring systems that are commonly used in clinical practice are Killip classification, thrombolysis in myocardial infarction (TIMI) score, and global registry of acute coronary event (GRACE) risk score system. ${ }^{4}$ The GRACE risk score system is a risk stratification system for ACS patients that is constructed based on ACS registry data, collected from various geographical locations. The system considers various variables to measure ACS patients' risk of mortality, including age, pulse rate, systolic blood pressure, Killip class, cardiac arrest, STsegment deviation, serum creatinine levels, and early status cardiac biomarkers. ${ }^{5}$

Correspondence: Dennis Bonang Tessy, Faculty of Medicine Universitas Padjadjaran, Jalan Raya Bandung Sumedang Km. 21 Jatinangor, Sumedang Indonesia, E-mail: dennistessy2@gmail.com 
The challenge of using the GRACE risk score system to estimate the risk of mortality for ACS patients in Indonesia is the possibility for geographical variation to influence the outcome of patient risk stratification. The predictors of in-hospital mortality for STEMI patients have been reported such as Killip class 3 and 4, anterior STEMI, tachycardia, arrhythmias, diabetes, late-onset, and without fibrinolysis. ${ }^{6}$ The aim of this study was to determine the in-hospital mortality characteristics of ACS patients treated in Dr. Hasan Sadikin General Hospital Bandung.

\section{Methods}

This descriptive cross-sectional study analyzed retrospective secondary data of ACS patients who died during hospitalization in the period of July 2018 to June 2019 that were recorded in the ACS registry. The study was conducted at Dr. Hasan Sadikin General Hospital Bandung from March 2020 to November 2020. The inclusion criteria for this study were adult ACS patients ( $\geq 18$ years) treated in Dr. Hasan Sadikin General Hospital Bandung from July 2018 to June 2019 who died from any cause (all-cause mortality) during treatment. The exclusion criteria were inaccessible, unreadable, and incomplete or lost patient medical record data. This study used the total sampling method.

The data for this study were retrieved following approval from the Research Ethics Committee of Universitas Padjadjaran no. 831/UN6.KEP/EC/202 and a Research Permit from the Health Research Ethics Committee of Dr. Hasan Sadikin General Hospital Bandung no. LB.02.01/X.6.5/3/2019.

The variables used in this study were diagnosis, age, gender, medical history (smoking history, diabetes mellitus,

Table In-Hospital Mortality of Acute Coronary Syndrome Patients in Dr. Hasan Sadikin General Hospital Bandung from July 2018 to June 2019

\begin{tabular}{lcc}
\hline & $\begin{array}{c}\text { Frequency } \\
\text { (n=17) }\end{array}$ & Average (min-max) \\
\hline Acute coronary syndrome & 11 & \\
STEMI & 6 & $64.1(48-82)$ \\
NSTEMI & & \\
Characteristics & & \\
Age (mean, years) & 7 & \\
Gender & 10 & \\
Male & & \\
Female & 10 & \\
Risk Factor & 4 & \\
Hypertension & 4 & \\
Diabetes mellitus & 1 & \\
Smoking habit (Active) & 4 & \\
Smoking habit (Ex-Smoker) & 1 & \\
Dyslipidemia & 9 & \\
Previous AMI & & \\
Multiple risk factors & 7 & \\
Killip Class & $57(28-134)$ \\
I & 1 & $13(4.4-18.7)$ \\
II & 4 & \\
III & & \\
Systolic BP (mean, mmHg) & & \\
Pulse rate (mean, beats/m) & & \\
Hemoglobin (mean, g/dL) & & \\
Leukocytes (mean, cells/ $\mu \mathrm{L})$ & 6 & \\
PCI & 11 & \\
PCI & & \\
Non-PCI & & \\
\hline
\end{tabular}

Note: AMI=Acute myocardial infarction; PCI=Percutaneous coronary intervention; STEMI=ST-segment elevation myocardial infarction; NSTEMI=Non-ST-segment elevation myocardial infarction 
hypertension, dyslipidemia, and previous acute myocardial infarction), clinical presentation (Killip class, blood pressure, and pulse rate), laboratory results (hemoglobin level and a number of leukocytes), and reperfusion therapy. The variables were presented as the frequency in percentage and mean. The percentage of findings in this study was based only on ACS patients that died and not ACS patients in general. Subgroup analysis was performed to observe the trend of in-hospital mortality characteristics according to gender, diagnosis, and Killip class. All collected data were performed using Microsoft Office Excel 2016.

\section{Results}

During the study, there were 365 ACS patient data found in ICD I21. Among those data, there were only 24 data that fulfill the inclusion criteria, and out of those 24 data, seven data were excluded because they were not found in the online registry.

Among a total of 17 ACS death cases, STEMI (11 of 17) was more in-hospital mortality compared to NSTEMI as shown in Table 1. In-hospital mortality characteristics of ACS patients that died during treatment were predominantly female $(n=10)$ with an average age of 64.1 years. The most common risk factor found among the patients was a history of hypertension, followed by smoking habits $(n=5)$. However, more than half of the subjects were observed to have multiple risk factors $(\mathrm{n}=9)$. There were more subjects found in Killip Class I than those in Killip Classes II, III, and IV. Most of the subjects did not undergo percutaneous coronary intervention (PCI) (11 of 17).

Based on gender, female patients were found to be older and had more STEMI diagnosis, a more frequent history of hypertension and dyslipidemia, and a higher mean systolic BP compared to male subjects. Based on the diagnosis, STEMI patients were older, had a more frequent history of hypertension, dyslipidemia, and previous AMI, more prevalent in Killip Class III and IV groups, and had a higher mean leukocyte count. Based on Killip Class groups, Killip Class IV had the highest mean age, hemoglobin levels, and leukocyte count, and the lowest mean systolic BP (data not shown).

\section{Discussions}

This study has explored the characteristic of patients who have died from ACS during hospitalization in Dr. Hasan Sadikin General Hospital Bandung. STEMI diagnosis has higher in-hospital mortality compared with NSTEMI, in accordance with a study result in another Indonesian city. ${ }^{6}$ This is likely due to the severe nature of STEMI.

Female is predominantly prevalent with a mean age of 64.1 years old. There is an increased risk of comorbidities found in the elderly population and the relatively high life expectancy in the area. The life expectancy in Bandung, West Java is 74.14 years, as reported by the National Central Agency of Statistics. ${ }^{8}$ However, other studies in Indonesia show different results which found predominantly male subjects with cardiac arrest or inhospital mortality. ${ }^{6,7}$ Furthermore, a study on gender associated with hospitalization outcomes in ACS patients shows that women have significantly worse outcomes and higher in-hospital mortality. The majority of female ACS patients are in the older age group with more comorbidities and received less frequent acute treatments and medical therapy for secondary prevention compared to their male counterparts. ${ }^{9,10}$ In a 2-year follow-up study on ACS patients in Dr. Hasan Sadikin General Hospital Bandung has found that in-hospital mortality is higher in female ACS patients, but the sex difference is no longer significant following clinical adjustment. ${ }^{11}$

In this study, a history of hypertension occurs in more than half of the cases, while a history of smoking, diabetes mellitus (DM), dyslipidemia, and previous acute myocardial infarction (AMI) are only found in less than half of the cases, similar with several other studies. ${ }^{7,12}$ The findings in this study are likely due to a high prevalence of chronic diseases among the elderly population. The most prevalent chronic disease found among the elderly is hypertension, followed by diabetes, heart disease, asthma, ulcer, and cancer. ${ }^{13}$

Killip classification is a clinical tool to identify heart failure in ACS patients. Class I is designated for those with no evidence of heart failure and Killip Class II, III, and IV for those showing signs of heart failure. ${ }^{14}$ Surprisingly in this study, the majority of the subjects has been found in Killip Class I, whereas the previous study shows the association of Killip Class with higher mortality. ${ }^{6}$ Interestingly, the 2-year follow-up study conducted by Nastiti ${ }^{11}$ found that the total deaths for patients in Killip Class I were similar to that in Killip Class IV. The high mortality found in the Killip Class I group is likely due to a high rate of 
patient admissions in the group. However, the proportion of mortality found when compared to the total patients in their corresponding Killip classes is still consistent with previous studies, where a high percentage of mortality can be seen in higher Killip classes (Killip Class $\geq$ II).

Pulse rate and systolic blood pressure (BP) can be used to assess the hemodynamic state of the patient. ${ }^{7}$ Vital signs measurements in this study reveal an average systolic BP of $106.8 \mathrm{mmHg}(60-160 \mathrm{mmHg})$ and an average pulse rate of 87 beats/min (28-134 beats/ min). This finding was slightly lower than the results found the emergency department. ${ }^{7}$ This was likely due to the delayed presentation found among the subjects in this study.

The hematologic examination has been proven to have diagnostic and prognostic value in cardiovascular diseases. Their relatively inexpensive cost and wide availability in daily clinical practice made them a potentially advantageous determinant in ACS patient risk stratification. ${ }^{15}$ An elevated WBC count (WBC $>10,000$ ) is related to a more advanced CAD and increased mortality among AMI and UA patients..$^{15}$ Furthermore, anemia $(\mathrm{Hb}<12 \mathrm{~g} /$ dl) on admission is associated with increased mortality in ACS patients. ${ }^{16,17}$ However, the mean $\mathrm{Hb}$ concentration found in this study is in the normal range.

In this study, the mortality in cases that did not undergo PCI was significantly higher than those who did. This result is in accordance with the data found in Jakarta Acute Coronary Syndrome (JACS) registry where the highest in-hospital mortality was found among non-reperfused patients. ${ }^{18}$ The reason for this failure to initiate reperfusion therapy is likely because the patient has died before therapy initiation, contraindications to initiating therapy, ineligibility for reperfusion therapy (onset $>12$ hours), or refusal to do the procedure. This study also found that more patients in Killip Class I were treated with PCI, in contrast with those in more severe Killip classes (Killip Class $\geq$ II). The severity and nature of the Killip classes likely influenced the decision to initiate PCI. The patients have shown progressively worsening hemodynamic status with higher Killip classification. Hence, in this study, the subjects in Killip Class I were likely stable enough to initiate reperfusion therapy, while those in Killip Class IV most likely died prior to undergoing PCI.

The relatively few samples have limited this study, thus, this study has not reflected the inhospital mortality characteristics of all ACS patients in Dr. Hasan Sadikin General Hospital Bandung. Moreover, there were no further laboratory examinations that can be used to evaluate other potential determinants in ACS patient mortality, hence, some findings have a trend result by previous literature.

To conclude, the in-hospital mortality in patients with acute coronary syndrome treated in Dr. Hasan Sadikin General Hospital Bandung are mostly diagnosed with STEMI, female $>60$ years old, with hypertension, Killip Class I and do not undergo PCI or no revascularization intervention.

\section{References}

1. Reed GW, Rossi JE, Cannon CP. Acute myocardial infarction. Lancet. 2017;389(10065):197-210.

2. World Health Organization. About cardiovascular diseases [Internet]. 2020 [cited 2020 Jun 23]. Available from: https://www.who.int/cardiovascular_ diseases/about_cvd/en/

3. Badan Penelitian dan Pengembangan Kesehatan Kementrian Kesehatan Republik Indonesia. Riset Kesehatan Dasar (Riskesdas) 2018. Jakarta: Badan Penelitian dan Pengembangan Kesehatan Kementrian Kesehatan Republik Indonesia; 2019.

4. Anggraini R, Wihastuti TA, Ningsih DK. The differences of correlation of the TIMI, GRACE, and Killip risk scores as predictor prognosis patients with non ST-elevation myocard infarction acute coronary syndrome in ICCU RSUD Dr. Iskak Tulungagung. Jurnal Ilmu Keperawatan. 2018;6(1):79-87.

5. EverettCC, Fox KAA, Reynolds C, Fernandez C, Sharples L, Stocken DD, et al. Evaluation of the impact of the GRACE risk score on the management and outcome of patients hospitalised with non-ST elevation acute coronary syndrome in the UK: protocol of the UKGRIS cluster-randomised registrybased trial. BMJ Open. 2019;9(9):e032165.

6. Gayatri NI, Firmansyah S, Hidayat S, Rudiktyo E. Prediktor mortalitas dalamrumah-sakit pasien infark miokard ST Elevasi (STEMI) akut di RSUD dr. Dradjat Prawiranegara Serang, Indonesia. CDK. 2016;43(3):171-4.

7. Ray M, Ruthazer R, Beshansky JR, Kent DM, Mukherjee JT, Alkofide $\mathrm{H}$, et al. A predictive model to identify patients with suspected acute coronary syndromes at high risk of cardiac arrest or in-hospital mortality: an 
IMMEDIATE Trial sub-study. Int J Cardiol Heart Vasc. 2015;9:37-42.

8. Badan Pusat Statistika. Data Kota Bandung 2018: indeks pembangunan manusia [Internet] [cited 2020 Nov 23]. Available from: https://ipm.bps.go.id/data/kabkot/ metode/baru/3273

9. Hao Y, Liu J, Liu J, Yang N, Smith Jr SC, Huo Y, et al. Sex differences in in-hospital management and outcomes of patients with acute coronary syndrome. Circulation. 2019;139(15):1776-85.

10. Gong IY, Goodman SG, Brieger D, Gale CP, Chew DP, Welsh RC, et al. GRACE risk score: Sex-based validity of in-hospital mortality prediction in Canadian patients with acute coronary syndrome. Int J Cardiol. 2017;244:24-9.

11. Nastiti G. Prediktor kematian dalam perawatan rumah sakit pada pasien sindrom koroner akut di RSUP Dr. Hasan Sadikin Bandung [dissertation]. Bandung: Universitas Padjadjaran; 2020.

12. Singh S, Paul S, Pal R, Thatkar P. Acute coronary syndrome-related mortality audit in a teaching hospital at Port Blair, India. J Family Med Prim Care. 2017;6(3):502-8.

13. Saquib N, Saquib J, Alhadlag A, Albakour MA, Aljumah B, Sughayyir M, et al. Chronic disease prevalence among elderly Saudi men. Int J Health Sci (Qassim). 2017;11(5):11-6.

14. El-Menyar A, Zubaid M, Almahmeed
W, Sulaiman K, Alnabti A, Singh R, et al. Killip classification in patients with acute coronary syndrome: Insight from a multicenter registry. Am J Emerg Med. 2012;30(1):97-103.

15. Budzianowski J, Pieszko K, Burchardt P, Rzeźniczak J, Hiczkiewicz J. The role of hematological indices in patients with acute coronary syndrome. Dis Markers. 2017;2017:3041565.

16. Mamas MA, Kwok CS, Kontopantelis E, Fryer AA, Buchan I, Bachmann MO, et al. Relationship between anemia and mortality outcomes in a National Acute Coronary Syndrome Cohort: Insights from the UK Myocardial Ischemia National Audit Project Registry. J Am Heart Assoc. 2016;5(11):e003348.

17. Moady G, Iakobishvili Z, Beigel R, Shlomo N, Matetzky S, Zahger D, et al. The predictive value of low admission hemoglobin over the GRACE score in patients with acute coronary syndrome. J Cardiol. 2019;73(4):271-5.

18. Dharma S, Andriantoro H, Purnawan I, Dakota I, Basalamah F, Hartono B, et al. Characteristics, treatment and in-hospital outcomes of patients with STEMI in a metropolitan area of a developing country: an initial report of the extended Jakarta Acute Coronary Syndrome registry. BMJ Open. 2016;6(8):e012193. 